\title{
A Prospective Observational Study Assessing the Relationship Between Solitary Thyroid Nodule Size and Incidence of Malignancy
}

\author{
Sherif Monib ${ }^{1}$, Nicholas Farkas ${ }^{2}$, Mohamed I. Abdelaziz ${ }^{3}$ \\ 1. Breast Surgery, West Hertfordshire Hospitals NHS Trust, St. Albans and Watford General Hospitals, London, GBR 2. \\ Surgery, West Hertfordshire Hospitals NHS Trust, St. Albans City Hospital, St. Albans, GBR 3. Surgery, Fayoum \\ University Hospital, Fayoum, EGY
}

Corresponding author: Sherif Monib, sherif.monib@nhs.net

\section{Abstract}

\section{Background}

Solitary thyroid nodule (STN) is a well-documented entity. Autopsy data indicate a 50\% prevalence of thyroid nodules $>10 \mathrm{~mm}$ in patients without clinical evidence of thyroid disease. Prevalence of palpable nodules is $4-7 \%$. Solitary thyroid nodules are often asymptomatic and found incidentally. Fine needle aspiration cytology is recommended to determine the nature of the thyroid nodule. $5-10 \%$ of the thyroid nodules are found to be malignant following thyroidectomy.

\section{Objective}

Our study aims to explore the relationship between solitary thyroid nodule size and malignancy.

\section{Methods}

A prospective, observational analysis looking at preoperative thyroid ultrasound scan findings and postoperative histology for a total of 100 female patients referred to our unit within a university hospital from November 2016 to April 2019. Statistical analysis including One-Way ANOVA was performed where appropriate.

\section{Results}

Total number of patients was 100 female patients divided according to the size of the nodule into three groups with the correlation between the size of the nodule and the incidence of malignancy.

Group A: Patients with a STN $<20 \mathrm{~mm}$; eight patients; post-operative histology = all benign.

Group B: Patients with a STN measuring 20-40 mm; 80 patients: 68 patients were benign, and 12 patients (12\%) were malignant (incidence of malignancy in the group is $15 \%$ ).

Review began 10/06/2020 Review ended 10/28/2020 Published 11/10/2020

(c) Copyright 2020

Monib et al. This is an open access article distributed under the terms of the Creative Commons Attribution License CC-BY 4.0., which permits unrestricted use, distribution, and reproduction in any medium, provided the original author and source are credited.
Group C: Patients with a STN $>40 \mathrm{~mm} ; 12$ patients: eight patients were benign, four patients were malignant, (incidence of malignancy $=33 \%$ ).

Correlation between the size of the nodule and the incidence of malignancy:

Group A: 0/8 malignancy; Group B: 12/80 patients were malignant; Group C: 4/12 malignant.

\section{Conclusion}

Our results suggest that the size of a solitary thyroid nodule cannot be reliably used for at predicting malignancy and should not be influencing patient's management.

Categories: Endocrinology/Diabetes/Metabolism, General Surgery

Keywords: thyroid, solitary thyroid nodule, ultrasound scan, thyroid cancer

\section{Introduction}

Solitary thyroid nodule is a common entity with autopsy data indicating a prevalence of $50 \%$ in patients with nodules larger than $1 \mathrm{~cm}$ without clinical evidence of thyroid disease. The prevalence of palpable nodules is $4-7 \%[1,2]$.

Thyroid nodules warrant removal when they are large enough to be symptomatic, or if there is a concern for 


\section{Cureus}

malignancy. The majority of nodules are asymptomatic. With 5-10\% of nodules being malignant, the decision to operate is made on therapeutic or diagnostic grounds [3, 4].

Most patients present with a large palpable thyroid nodule. However, some solitary thyroid nodules are incidentally found on imaging studies performed for other reasons [5].

Barroeta et al. found that a single dominant or solitary nodule is more likely to represent carcinoma than a single nodule within a multi-nodular gland. The incidence of malignancy increased from 2.7 to $30 \%$ and from 1.4 to $10 \%$, respectively [6].

Important elements in a patient's history increase the likelihood of malignancy, these include prior head and neck irradiation, rapid nodule growth, dysphagia, dysphonia, male gender, presentation at extremes of age $(<20$ years or $>70$ years) and family history of medullary thyroid carcinoma or multiple endocrine neoplasia $[7,8]$.

\section{Aim of our study}

This study aims to determine the relationship between size and the incidence of malignancy in patients with a solitary thyroid nodule.

\section{Materials And Methods}

We conducted a prospective, observational analysis looking at preoperative thyroid ultrasound scan findings and post-operative histology for a total of 100 female patients referred to our unit within a university hospital from November 2016 to April 2019.

The study was approved by the local medical ethics committee. Inclusion criteria: female patients only (to eliminate sex-related bias) who were found to have a solitary thyroid nodule on neck ultrasound scan. All selected patients were euthyroid and fit for general anaesthesia. Exclusion criteria: male patients, patients with diffusely enlarged thyroid gland, patients not fit for general anaesthesia, recurrent cases and patients with thyrotoxicosis.

All patients were euthyroid on preoperative blood tests and underwent a preoperative neck ultrasound scan and an ultrasound-guided fine-needle aspiration cytology (FNAC).

\section{Statistical analysis}

Data were collected and coded to facilitate data manipulation and double entered into Microsoft Access and data analysis was performed using Statistical Package of Social Science (SPSS) software version 18 (IBM Corp., Armonk, NY) in windows 7.

\section{Results}

Total number of patients included in our analysis was 100 patients; their age range was 20-55 years with mean \pm SD $33 \pm 9.5$ years, 56 patients $(56 \%)$ were younger than 30 years, 28 patients (28\%) were 30 - 40 years, 12 patients (12\%) were $40-50$ years and four patients (4\%) were older than 50 (Table 1 ).

\begin{tabular}{|l|l|l|}
\hline Age & No. & $\%$ \\
\hline$<30 y$ & 56 & $56 \%$ \\
\hline $30-40 y$ & 28 & $28 \%$ \\
\hline $0-50 y$ & 12 & $12 \%$ \\
$>50 y$ & 4 & $4 \%$ \\
\hline Total & 100 & $100 \%$ \\
\hline Min.-Max. & 100 & \\
Mean \pm SD & $20-55$ ys & \\
\hline
\end{tabular}

TABLE 1: Distribution of studied sample according to patient's age

Patients were divided according to the maximum diameter size of the solitary thyroid nodule on ultrasound scan. Similar categories were used for both pre-operative and post-operative size: group (A): less than 20 


\section{Cureus}

$\mathrm{mm}$, group (B): 20-40 $\mathrm{mm}$, and group (C) greater than $40 \mathrm{~mm}$. Pre-operative ultrasound and post-operative histopathology reports demonstrated minimal difference $\pm 1-2 \mathrm{~mm}$ between the two groups (Table 2).

\begin{tabular}{|c|c|c|}
\hline Nodule size in each group & Size by US & Size in post-operative pathology \\
\hline Group (A): size $<2 \mathrm{~cm}$ & $8(8 \%)$ & $8(8 \%)$ \\
\hline Group (B): size $2-4 \mathrm{~cm}$ & $80(80 \%)$ & $80(80 \%)$ \\
\hline Group (C): size >4 cm & $12(12 \%)$ & $12(12 \%)$ \\
\hline Total & $100(100 \%)$ & $100(100 \%)$ \\
\hline Min.-Max. & $1.5 \mathrm{~cm}-5 \mathrm{~cm}$ & \\
\hline Mean \pm S.D. & $\mathrm{cm} \pm 1.5 \mathrm{~cm}$ & \\
\hline
\end{tabular}

TABLE 2: Distribution of the studied sample according to the nodule size in preoperative ultrasound (US) compared to nodule size in postoperative histopathology reports.

Pre-operative FNAC revealed that 20 patients (20\%) had colloid adenoma, 48 patients $(48 \%)$ had a follicular lesion, 28 patients (28\%) had papillary adenoma, four patients (4\%) had papillary thyroid carcinoma (Table 3).

\begin{tabular}{|c|c|c|}
\hline Pre-operative FNAC & Number & $\%$ \\
\hline Colloid adenoma & 20 & $20 \%$ \\
\hline Follicular lesion & 48 & $48 \%$ \\
\hline Papillary adenoma & 28 & $28 \%$ \\
\hline Papillary carcinoma & 4 & $4 \%$ \\
\hline Total & 0 & 10 \\
\hline
\end{tabular}

TABLE 3: Distribution of studied sample according to pre-operative FNAC results.

FNAC: Fine-needle aspiration cytology

A total of 80 patients ( $80 \%$ ) had hemi-thyroidectomy of the affected lobe. Exploration of the contralateral lobe was carried out for all patients. Fine nodularity was found in 20 patients (20\%). Total thyroidectomy with lymph node dissection was carried out for the four patients with carcinoma.

Post-operative histopathology results were divided into two groups:

Benign: 84 patients (84\%) - 20 colloid adenoma, 36 follicular adenoma, 20 patients (20\%) were papillary adenoma and eight patients (8\%) were papillary adenoma with cystic degeneration; Malignant: 16 patients (16\%) - 12 follicular carcinoma and four papillary carcinomas (Table 4). 


\section{Cureus}

Post-operative histopathology

Colloid adenoma

Follicular adenoma

Papillary adenoma

Papillary adenoma \& cystic degeneration

Follicular carcinoma

Papillary carcinoma

Total
$\%$

$20 \%$

20

$36 \%$

36

20

$20 \%$

$8 \%$

12

$12 \%$

$4 \%$

100

TABLE 4: Distribution of studied sample according to patient's post-operative histopathology.

Based on histological size of the solitary thyroid nodule, patients were divided into three groups; Group A: (thyroid nodule $<20 \mathrm{~mm}$ ) included eight patients $(8 \%)$, all had follicular adenoma. Group B: (thyroid nodule $20-40 \mathrm{~mm}) 80$ patients (80\%), of which 68 patients were benign, 12 patients (12\%) were

malignant (incidence of malignancy in the group is $15 \%$ ). Breakdown of histology: 16 patients had a colloid adenoma, 28 patients with papillary adenoma, 24 patients with follicular adenoma, eight patients with follicular carcinoma and four patients had papillary carcinoma. Group C: (thyroid nodule $>40 \mathrm{~mm}$ ) included 12 patients (12\%), eight patients were benign (four patients had a follicular adenoma, four patients colloid adenoma), four patients were malignant (follicular carcinoma). The incidence of malignancy in this group was $33 \%$. Nodule size ranged between $1.5-50 \mathrm{~mm}$ (mean $\pm \mathrm{SD}$ is $3.5 \pm 1.5 \mathrm{~cm}$ ) (Table 4 ).

Correlation between the size of the nodule and the incidence of malignancy:

Group A: 0/8 malignancy. Group B: 12/80 patients were malignant. Group C: 4/12 malignant (Table 5).

\begin{tabular}{|c|c|c|}
\hline Groups of nodule size & Benign No. (\%) & Malignant No. (\%) \\
\hline Group A: $<20$ mm & 8 patients $(8 \%)^{*}$ & $0(0 \%)^{*}$ \\
\hline Group B: $20-40 \mathrm{~mm}$ & 68 patients $(68 \%)^{*}$ & 12 patients $(12 \%)^{x}$ \\
\hline Group C: >40 mm & 8 patients $(8 \%)^{\star}$ & 4 patients $(4 \%)^{\star}$ \\
\hline
\end{tabular}

TABLE 5: Distribution of studied sample according to patient's post-operative histopathology in correlation with the incidence of malignancy.

* The percentage to the total number in the study $(n=100)$

\section{Discussion}

Thyroid nodules are observed in $8 \%$ of the adult population and seen more frequently in women than men. A solitary thyroid nodule is defined clinically as a localized thyroid enlargement with an apparently normal remaining gland. Such nodules carry a 5-15\% prevalence of malignancy. Thyroid malignancies account for approximately $1 \%$ of all malignant neoplasms and are the most common endocrine neoplasia. With the use of ultrasound, up to 10 times more nodules are thought to be detected. They are found in $4 \%-8 \%$ of adults by palpation and in $13 \%-67 \%$ when ultrasound detection is utilized. In autopsy studies, they have a prevalence of approximately 50\% [9-11].

Tai Jun et al. concluded that male gender, microcalcification and lymphadenopathy are independent risk factors for predicting malignancy in patients with STN; patients with more than two of those risk factors should be subjected to further examination or thyroidectomy [9].

Some studies suggested that the size of a solitary thyroid nodule can be considered as an independent predictor for risk of malignancy, especially in the presence of underlying risk factor. McCoy et al. concluded that due to high false-negative rate for preoperative benign cytology, thyroid nodules greater than or equal to $4 \mathrm{~cm}$ should be considered for diagnostic lobectomy regardless of fine-needle aspiration biopsy (FNAB) 
results $[12,13]$.

In our study, patient age ranged between 20 - 55 years with mean \pm SD $33 \pm 9.5$ years demonstrating a younger age on average when compared with other studies. Godazandeh et al. found the mean ages of the patients to be $41.56 \pm 13.24$ years (between 13 and 86 years old) [14].

Pre-operative FNAC results contrasted with the final post-operative histology results as it showed that $48 \%$ had follicular lesions, and only picked four cases of papillary carcinoma.

Fine-needle aspiration cytology of thyroid nodule was introduced over 50 years ago, and quickly gained popularity to be an important part of thyroid nodule assessment, yet $20 \%$ of samples were reported to be indeterminate $[15,16]$. Musani et al. found in their study that the sensitivity of FNAC of thyroid nodules was $61.53 \%$ and specificity was $98.9 \%$ [17]. Shere et al. divided the patients according to the result of preoperative FNAC into four groups: inadequate, benign, malignant, and suspicious. Results demonstrated that FNAC cannot distinguish between follicular adenoma and follicular carcinoma [18].

Intra-operative exploration of the contralateral thyroid lobe in our patients demonstrated that $80 \%$ of the contralateral lobes were free from nodularity while 20 patients (20\%) showed fine nodularity. Twelve patients underwent total thyroidectomy. McCoy et al. found that in $70 \%$ of their patients the contralateral lobe was free from nodularity, in $30 \%$ of patients the contralateral lobe demonstrated fine nodularity, whilst $5 \%$ of patients underwent total thyroidectomy [13]. Both our results and those of other studies highlight the importance of intra-operative exploration of the contralateral thyroid lobe in order to identify any nodularity not identified on pre-operative neck ultrasound scan.

When looking at the correlation between the size of the nodule and the incidence of malignancy, we found that smaller nodules appear linked to benign findings, whilst larger nodules were associated with a greater incidence of malignancy. Kamran et al. reported that increasing thyroid nodule size had an influence on cancer risk in a nonlinear fashion with no increase in risk beyond the $20 \mathrm{~mm}$ threshold [5]. McCoy et al. reported a higher prevalence of thyroid carcinoma in nodule sizes $\geqslant 40 \mathrm{~mm}$ [13]. Berker et al. also described no significant difference between $10 \mathrm{~mm}$ and $40 \mathrm{~mm}$ nodules in thyroid malignancy risk [19]. Conversely, Rausei et al. and McHenry et al. reported a higher prevalence of thyroid carcinoma in smaller nodules $[20,21]$.

Three studies demonstrated a higher risk of malignancy in nodules $\geqslant 40 \mathrm{~mm}$ compared to $<40 \mathrm{~mm}$ : Bestepe et al. reported a risk of malignancy $24 \%$ in nodules $\geqslant 40 \mathrm{~mm}$ versus $12 \%$ in nodules $<40 \mathrm{~mm}$ in 571 patients [22], Kuru et al. [23] reported a risk of $58.2 \%$ in nodules $\geqslant 4 \mathrm{~cm}$ versus $37.3 \%$ in nodules $<40 \mathrm{~mm}$ in 159 patients and Kamran et al. [5] reported a risk of $15 \%$ in nodules $\geqslant 40 \mathrm{~mm}$ versus $12.3 \%$ in nodules $<40 \mathrm{~mm}$ in 4955 patients.

In our study, we observed that the incidence of malignancy in nodules $<40 \mathrm{~mm}$ was $15 \%$ versus $33 \%$ in nodules $>40 \mathrm{~mm}$. The risk of malignancy in each group does not appear to increase in a linear manner, and One-Way ANOVA showed no statistically significant difference between malignant and benign nodules in size. Therefore nodule size cannot be considered as a dependent risk factor of malignancy in STN.

There is no international consensus linking an increased risk of malignancy with increased size of thyroid nodules. Therefore thyroid nodule evaluation should aim to accurately assess the malignancy risk via methods that are accurate, precise, yet also safe and cost-effective [24].

Ozel et al. concluded that thyroid nodules can be characterized effectively by using ultrasound scan yet ultrasound features used in this distinction vary in relation to nodule size [25]. Zhao et al. concluded that nodule size estimated by ultrasound (US) shows relatively good correlation with final pathologic size. However, thyroid nodules should undergo FNA regardless of size [26].

While Hong et al. found that the impact of nodule size on the malignancy risk differed according to the US pattern. A large nodule size $\geqslant 30 \mathrm{~mm}$ showed a higher malignancy risk than smaller nodules in intermediateand low-suspicion nodules [27]. Zhao et al. concluded that thyroid nodule size is inversely related to malignancy risk, as larger nodules have lower malignancy rates [26]. Our findings support the results of other studies highlighting that there is still uncertainty in relation to the impact of the size of a solitary thyroid nodule and the risk of malignancy.

\section{Conclusions}

Management of solitary thyroid nodules is based on clinical assessment, ultrasound scan findings and preoperative fine-needle aspiration cytology findings. Our results suggest that increasing size of a solitary thyroid nodule may be a predictor for malignancy.

Nevertheless, size of STN cannot be reliably used for predicting malignancy; we advocate thorough preoperative workup to ensure potential malignancies are not missed. We recommend a multicentric study 
including a large number of patients to ascertain the relation between size and incidence of malignancy in a solitary thyroid nodule.

\section{Additional Information \\ Disclosures}

Human subjects: Consent was obtained by all participants in this study. Fayoum University Hospital medical ethics committee issued approval Not applicable. The study was approved by the medical ethics committee at Fayoum University Hospital. Animal subjects: All authors have confirmed that this study did not involve animal subjects or tissue. Conflicts of interest: In compliance with the ICMJE uniform disclosure form, all authors declare the following: Payment/services info: All authors have declared that no financial support was received from any organization for the submitted work. Financial relationships: All authors have declared that they have no financial relationships at present or within the previous three years with any organizations that might have an interest in the submitted work. Other relationships: All authors have declared that there are no other relationships or activities that could appear to have influenced the submitted work.

\section{References}

1. Mortensen JD, Woolner LB, Bennet WA: Gross and microscopic findings in clinically normal thyroid glands . J Clin Endocrinol Metab. 1955, 15:1270-1280. 10.1210/jcem-15-10-1270

2. Singer PA: Evaluation and management of the solitary thyroid nodule . Otolaryngol Clin North Am. 1996, 29:577-591.

3. Papini E, Guglielmi R, Bianchini A, et al.: Risk of malignancy in nonpalpable thyroid nodules: predictive value of ultrasound and color-Doppler features. J Clin Endocrinol Metab. 2002, 87:1941-1946. 10.1210/jcem.87.5.8504

4. Nam-Goog IS, Kim HY, Gong G, Lee HK, Hong SJ, Kim WB, Shong YK: Ultrasonography-guided fine-needle aspiration of thyroid incidentaloma: correlation with pathological findings. Clin Endocrinol. 2004, 60:21-28. 10.1046/j.1365-2265.2003.01912.x

5. Kamran SC, Marqusee E, Kim MI, et al.: Thyroid nodule size and prediction of cancer. J Clin Endocrinol Metab. 2013, 98:564-570. 10.1210/jc.2012-2968

6. Barroeta JE, Wang H, Shiina N, Gupta PK, Livolsi VA, Baloch ZW: Is fine-needle aspiration (FNA) of multiple thyroid nodules justified?. Endocr Pathol. 2006, 17:61-66. 10.1385/EP:17:1:61

7. Ferrone S, Marincola FM: Loss of HLA class 1 antigens by melanoma cells: molecular mechanisms, functional significance and clinical relevance. Immunol Today. 1995, 16:487-494. 10.1016/01675699(95)80033-6

8. Hegedus L: The thyroid nodule. N Engl J Med. 2004, 351:1764-1771. 10.1056/NEJMcp031436

9. Tai Jun D, Yang Jin L, Wu Si C, Wang Bin W, Chang Cong J: Risk factors for malignancy in patients with solitary thyroid nodules and their impact on the management. J Can Res Ther. 2012, 8:379-383. 10.4103/0973-1482.103516

10. Li H, Li J: Thyroid disorders in women. Minerva Med. 2015, 106:109-114.

11. Frates MC, Benson CB, Doubilet PM, et al.: Prevalence and distribution of carcinoma in patients with solitary and multiple thyroid nodules on sonography. J Clin Endocrinol Metab. 2006, 91:3411-3417. 10.1210/jc.2006-0690

12. Wienke JR, Chong WK, Fielding JR, Zou KH, Mittelstaedt CA: Sonographic features of benign thyroid nodules. J Ultrasound Med. 2003, 22:1027-1031. 10.7863/jum.2003.22.10.1027

13. McCoy KL, Jabbour N, Ogilvie JB, Ohori NP, Carty SE, Yim JH: The incidence of cancer and rate of falsenegative cytology in thyroid nodules greater than or equal to $4 \mathrm{~cm}$ in size. Surgery. 2007, 142:837-844. 10.1016/j.surg.2007.08.012

14. Godazandeh G, Kashi Z, Zargarnataj S, Fazli M, Ebadi R, Kerdabadi EH: Evaluation the relationship between thyroid nodule size with malignancy and accuracy of fine needle aspiration biopsy (FNAB). Acta Inform Med. 2016, 24:347-350. 10.5455/aim.2016.24.347-350

15. Gharib H, Goellner JR: Fine-needle aspiration biopsy of the thyroid: an appraisal . Am Intern Med. 1993, 118:282-289. 10.7326/0003-4819-118-4-199302150-00007

16. Yassa L, Cibas ES, Benson CB, et al.: Long-term assessment of a multidisciplinary approach to thyroid nodule diagnostic evaluation. Cancer. 2007, 111:508-516. 10.1002/cncr.23116

17. Musani MA, Khan FA, Malik S, Khambaty Y: Fine needle aspiration cytology: sensitivity and specificity in thyroid lesions. J Ayub Med Coll Abbottabad. 2011, 23:34-36.

18. Shere SK, Kulkarni AS, Phulgirkar PP, Anjum S, Patil SP, Bindu R: Correlation of fine needle aspiration cytology with histopathology in diagnosis of thyroid lesions. J Evol Medical Dental Sci. 2013, 2:4826.

19. Berker D, Aydin Y, Ustun I, et al.: The value of fine-needle aspiration biopsy in subcentimeter thyroid nodules. Thyroid. 2008, 18:603-608. 10.1089/thy.2007.0313

20. Rausei S, Dionigi G, Frattini F, et al.: Nodule size and fine-needle aspiration biopsy: diagnostic challenges for thyroid malignancy. Am J Surg. 2011, 201:525-530. 10.1016/j.amjsurg.2010.03.008

21. McHenry CR, Huh ES, Machekano RN: Is nodule size an independent predictor of thyroid malignancy? . Surgery. 2008, 144:1062-1069. 10.1016/j.surg.2008.07.021

22. Bestepe N, Ozdemir D, Tam AA, et al.: Malignancy risk and false-negative rate of fine needle aspiration cytology in thyroid nodules $\geqslant 4.0 \mathrm{~cm}$. Surgery. 2016, 160:405-412. 10.1016/j.surg.2016.03.019

23. Kuru B, Gulcelik NE, Gulcelik MA, Dincer H: Predictive index for carcinoma of thyroid nodules and its integration with fine-needle aspiration cytology. Head Neck. 2009, 31:856-866. 10.1002/hed.21049

24. Cooper DS, Doherty GM, Haugen BR, et al.: Revised American Thyroid Association management guidelines for patients with thyroid nodules and differentiated thyroid cancer. Tyroid. 2009, 19:1167-1213. 


\section{Cureus}

10.1089/thy.2009.0110

25. Ozel A, Erturk SM, Ercan A, et al.: The diagnostic efficiency of ultrasound in characterization for thyroid nodules: how many criteria are required to predict malignancy?. Med Ultrason. 2012, 14:24-28.

26. Zhao L, Yan H, Pang P, et al.: Thyroid nodule size calculated using ultrasound and gross pathology as predictors of cancer: a 23-year retrospective study. Diagn Cytopathol. 2019, 47:187-193. 10.1002/dc.24068

27. Hong MJ, Na DG, Baek JH, Sung JY, Kim JH: Impact of nodule size on malignancy risk differs according to the ultrasonography pattern of thyroid nodules. Korean J Radiol. 2018, 19:534-541.

10.3348/kir.2018.19.3.534 